\title{
The impact of violence on Iraqi junior doctors
}

\begin{abstract}
Background: Iraqi doctors are leaving Iraq mainly because of violence. We set this study to dig for the consequences of violence on the Iraqi doctors via exploring their suffering and their plans to stay in or leave the country.

Methods: This study included 323 junior resident doctors from 20 teaching hospitals in Baghdad. The questionnaire focused on the doctors suffering, their exposure (or their families) to any form of violence, and their perspective about their future.

Findings: Fewer than two thirds (65\%) said that they have been exposed to violent behavior while being in duty, or out of duty $(37.2 \%), 18.6 \%$ reported a history of being arrested, kidnapped or injured, $42.1 \%$ had one of their family members (and $76.8 \%$ had one of their colleagues) being killed, kidnapped or injured during the last 10 years, $79.6 \%$ are exposed to pressure at work, $89.5 \%$ stated that it is safer to leave Iraq, and $76.5 \%$ are thinking of leaving the country. Data analysis revealed that there is a statistically significant association between doctors' exposure to different forms of violence $(\mathrm{p}=.002)$ or their families $(\mathrm{p}=.041)$ and their thinking of leaving Iraq.
\end{abstract}

Interpretation: Most of the junior doctors are not satisfied with their career, or with their living status that is of high risk and gloomy future. The continuous depletion of brains and expertise will seriously affect the staffing level (quantitatively and qualitatively) leading to more deterioration in the quality and availability of the (currently limping) health care services.

Keywords: violence, impact, iraq, junior, doctors
Volume 5 Issue I - 2017

\author{
Ameel F Al-Shawi,' Waleed A Tawfeeq,' Saba \\ Dhiaa, ${ }^{2}$ Riyadh K Lafta ${ }^{3,4}$ \\ 'College of Medicine, University of Fallujah, Iraq \\ ${ }^{2}$ College of Medical Technologies, Baghdad, Iraq \\ ${ }^{3}$ College of Medicine, Mustansiriya University, Iraq \\ 4Professor in University of Washington, USA
}

Correspondence: Ameel FAI-Shawi, College of Medicine, University of Fallujah, Iraq, Email ameelalshawi@gmail.com

Received: October 18, 2016 | Published: January 27, 2017
Abbreviations: IDMC, internal displacement monitoring center; IDPs, internally displaced persons; SPSS, statistical packages for social sciences

\section{Introduction}

While violence against healthcare workers is a global problem, health-care workers in war zones are even more prone to these violent acts with more serious consequences. ${ }^{1}$ After USA invasion in 2003, Iraqi academics (and doctors in particular) faced intolerable levels of violence and systematic targeting. ${ }^{2}$ They are exposed to assassination, kidnapping, threats, and forced displacement, especially in Baghdad where the security failure is at its most. The rate of violent events among Iraqi specialist doctors during 2004-2007 was estimated to be $3.7 \%$, and the rate of violent death at $1.6 \%$. The Iraqi government has displayed no effectiveness in protecting Iraq's brightest minds, and the killers are never being brought to justice. ${ }^{3}$ Repeated assaults is another trend of violence, in a 2008 survey that included four emergency department physicians, $80 \%$ of the physicians reported an assault by a patient or a family member, $38 \%$ of which involved a gun threat. ${ }^{4}$ On the other hand, the wages (Mean \$5000-6000 annually) remain relatively low and discouraging considering the workload and increasing risks. ${ }^{5}$ The revival plan of the Iraqi health care system seems to be very slow and limping; lack of security, bad management, politicization of the Ministry of Health, and corruption, are all problems that decision makers have failed to solve..$^{6-11}$

Thirteen years elapsed since the 2003 war in Iraq and still no light emerged at the end of the tunnel. Iraqi doctors are getting assaulted, violated, and humiliated, and as a result, more physicians are leaving the country seeking a safer place, $70 \%$ of Iraq's fully qualified physicians left the country to seek asylum in other countries due to violent deaths $(1 \bullet 65 \%)$, threats $(3 \%)$, and kidnappings $(0 \bullet 67 \%))^{12}$ Many of those leaving their posts were senior doctors, resulting in a critical leadership void and in some cases, the complete disappearance of certain specialties. ${ }^{13}$ By 2008, of 34,000 physicians registered in Iraq before the 2003 invasion, an estimated 20,000 have left, 2,000 been murdered, and more than 250 have been kidnapped. ${ }^{14}$

The World Health Organization reported that Iraq is continuing to face a severe shortage of healthcare professionals; it is ranked 95 globally and is in the bottom of the list of the regional countries. ${ }^{15}$. The World Health Organization and World Bank estimated the growth of physician-to-population ratio in Iraq to be 5.5 per 10,000 populations in 1990, 5.0 in 2002, 6.3 in 2004, 6.6 in 2005, 6.1 in 2006, and 6.9 in 2012 , which is much lower than the regional rate $(10.9$ per 10,000$)$ and adjacent countries such as Iran (8.9), Kuwait (17.9), Turkey (15.4), Syria (15.0), Saudi Arabia (9.4), and Jordan (24.5)..$^{15-17}$ These shortages, in turn, contribute substantially to the weakness of health systems and obstruct the achievement of public health goals. ${ }^{18}$ We set this study to dig for the impact of violence on the Iraqi junior doctors via exploring their suffering in their career (mainly through exposure to violence), and their plans to stay in or leave the country.

\section{Methods}

This cross sectional study was conducted during the period from July through August 2016 in 20 major and teaching hospitals in Baghdad. We chose a convenient sample of resident junior doctors that are either newly graduated from the Medical Schools or are candidates of postgraduate (Board) studies. We constructed a questionnaire form that focused mostly on the suffering of those doctors, their exposure (or their families) to any form of violence, and their perspective about their future and whether they do (or do not) plan to leave their mother 
country. The questionnaire inquired about the exposure of doctors to any sort of violence including exposure to insult, assaults, threats, being arrested, kidnapped or intentionally injured, also exposure of their colleagues or family members to any sort of violence (killed, kidnapped or injured), whether any of their seniors or colleagues have left the country to escape the risk of violence, whether they have frequently seen bodies or injured people on the road, and if they are exposed to any notable pressure in their job. As English is the language of instruction in all the Iraqi medical schools, so, we developed our questionnaire in English. The questionnaire was selfadministered by the respondents after taking their verbal consent and explaining to them the purpose of the study, giving them the full choice to participate, and assuring them that all the information will be kept strictly confidential and will not be used by anyone other than the authors, and for any purposes other than research work. The form was anonymous. Data collection was performed by two Community physicians with a long experience in field work. The process was done through distributing the forms to the junior doctors and collecting it from them in the next day.

\section{Analysis of data}

Was carried out using the available statistical package of SPSS22 (Statistical Packages for Social Sciences- version 22). Data was presented in simple measures of frequency, percentage, mean, standard deviation, and range (minimum-maximum values). The significance of association was tested using Pearson Chi-square test with Yate's correction or Fisher Exact test whenever applicable. Statistical significance was considered with $\mathrm{P}$ value equal or less than 0.05 .

\section{Results}

A total of 400 forms were distributed and only 323 were collected giving a response rate of $81 \%$. Junior doctors age ranged from 24-39 (mean $29.5+3.8$ ), with $55.1 \%$ males and $44.9 \%$ females, half of the sample $(50.8 \%)$ was postgraduate (Board) candidates, $27.2 \%$ rotators and $22 \%$ permanent residents, they were graduated from different medical schools (from Baghdad and other governorates), the monthly income for the vast majority $(90 \%)$ of them was less than $\$ 1000$, as shown in Table $1 \& 2$ depicts the doctors exposure to different forms of violence, more than three quarters $(77.7 \%)$ mentioned that they were insulted or assaulted during their duty by the relatives of the patients, fewer than two thirds $(65 \%)$ said that they have been exposed to violent behavior while being in duty, $37.2 \%$ were exposed to violence out of duty, and $18.6 \%$ reported a history of being arrested, kidnapped or (intentionally) injured. They also said that they (42.1\%) have at least one of their family members (and 76.8\% had one of their colleagues) being killed, kidnapped or injured during the last 10years. All the doctors $(100 \%)$ reported that some of their seniors or colleagues have left the country to escape violence. The doctors also said that they are exposed to pressure in their job (79.6\%), and that there are obstacles at the work $(82.4 \%)$, at home (26\%),transportation $(40.2 \%)$, in making their living $(45.2 \%)$, and in their career $(50.2 \%)$. They said that the highest risk on their life is at the work place $(50.2 \%)$ or in the street $(40.2 \%)$, and on a scale of 1 (minimum) to 10 (maximum), notably, $93.8 \%$ of them scaled it to be more than 5 .

With respect to their future perspective; $89.5 \%$ stated that it is safer to leave Iraq, $76.5 \%$ are thinking of leaving the country and $80.5 \%$ have no hope at all that Iraq could get better or be a suitable place to live in the near future. The data analysis revealed that there is a statistically significant association between doctors' exposure to repeated insult, assaults, or threats and thinking of leaving the country $(\mathrm{p}=.004)$. Thinking of leaving Iraq was also significantly associated with doctors exposure $(\mathrm{p}=.002)$ or any member of their families $(\mathrm{p}=.041)$ to any sort of violence. Thinking of leaving Iraq was significantly more among those who believe that Iraq is neither now $(\mathrm{p}=.0001)$ nor will $(\mathrm{p}=.0001)$ in the near future be a safe place to live in Table 3.

Table I Demographic characteristics of the study sample: age range (24-39) with mean of $29.5 \pm 3.8$

\begin{tabular}{llll}
\hline & & No. & $\%$ \\
\hline \multirow{3}{*}{ Gender } & Male & 178 & 55.1 \\
& Female & 145 & 44.9 \\
& Baghdad & 150 & 46.4 \\
& Mustansiriya & 85 & 26.3 \\
& Nahrain & 23 & 7.1 \\
University of graduation: & Mosul & 21 & 6.5 \\
& Kufa and Tikrit & 16 & 5 \\
& Others & 28 & 8.7 \\
& Rotator & 88 & 27.2 \\
Specialty: & Permanent resident & 71 & 22 \\
& Board candidate & 164 & 50.8 \\
Monthly income: & $<\$ 1000$ & 291 & 90.1 \\
Total & $>\$ 1000$ & 32 & 9.9 \\
\hline
\end{tabular}

Table 2 Frequency of doctor's exposure to different forms of violence and their opinion about risk

\begin{tabular}{lll}
\hline & No. & $\%$ \\
\hline Being repeatedly insulted, assaulted, or threatened while being in duty & $25 \mathrm{I}$ & 77.7 \\
Exposure to any sort of violence while being in duty & 210 & 65 \\
Exposure to any sort of violence out of duty & 120 & 37.2 \\
Forced to pay a (Tribal penalty) for the medical/surgical complications of the patients & 33 & 10.2 \\
Being arrested, kidnapped, or injured (violently) during the last I0 years & 60 & 18.6 \\
Family members being killed, kidnapped, or injured (violently) in the last 10 years & 136 & 42.1 \\
Seniors/ colleagues being killed, kidnapped, or injured (last I0 years) & 248 & 76.8
\end{tabular}


Table Continued.

\begin{tabular}{|c|c|c|c|}
\hline & & No. & $\%$ \\
\hline & $<10$ & 179 & 55.4 \\
\hline \multirow[t]{2}{*}{ Colleagues left Iraq to escape violence } & $10---19$ & 92 & 28.5 \\
\hline & $=>20$ & 52 & 16.1 \\
\hline \multirow[t]{2}{*}{ Have frequently seen injured people or dead bodies on the road } & & 236 & 73.1 \\
\hline & Many & 228 & 70.6 \\
\hline \multirow[t]{2}{*}{ Have seen cases of violent injury or death during work } & Some & 72 & 22.3 \\
\hline & Few & 23 & 7.1 \\
\hline Exposure to any kind of pressure while doing their job & & 257 & 79.6 \\
\hline Feeling restricted at work due to deficient medicines or equipment & & 291 & 90.1 \\
\hline \multicolumn{4}{|l|}{ Presence of obstacles facing doctors in Iraq } \\
\hline -At the work place & & 266 & 82.4 \\
\hline -Home & & 84 & 26 \\
\hline -Transportation & & 130 & 40.2 \\
\hline -Making living & & 146 & 45.2 \\
\hline \multirow[t]{3}{*}{-Career development } & & 162 & 50.2 \\
\hline & Home & 6 & 1.9 \\
\hline & Street & 130 & 40.2 \\
\hline \multirow[t]{6}{*}{ The highest risk is at: } & Work & 162 & 50.2 \\
\hline & Markets & 2 & 0.6 \\
\hline & All & 23 & 7.1 \\
\hline & 5-Jan & 20 & 6.2 \\
\hline & 6 & 20 & 6.2 \\
\hline & 7 & 74 & 22.9 \\
\hline \multirow{3}{*}{ Level of risk on a scale of I (minimum) to I0 (Maximum) } & 8 & 96 & 29.7 \\
\hline & 9 & 55 & 17 \\
\hline & 10 & 58 & 18 \\
\hline Going outside Iraq is safer for doctors & & 289 & 89.5 \\
\hline Thinking of leaving Iraq and work/live outside & & 247 & 76.5 \\
\hline Any chance that Irag will be a suitable place to live in the near future? & & 63 & 19.5 \\
\hline
\end{tabular}

Table 3 Association between exposure to violence and thinking of leaving Iraq $(n=323)$

\begin{tabular}{|c|c|c|c|c|c|c|}
\hline & & \multicolumn{4}{|c|}{$\begin{array}{l}\text { Are you thinking of leaving } \\
\text { Iraq }\end{array}$} & \multirow{3}{*}{$\begin{array}{l}P \\
\text { Value }\end{array}$} \\
\hline & & \multicolumn{2}{|l|}{ Yes } & \multicolumn{2}{|l|}{ No } & \\
\hline & & No. & $\%$ & No. & $\%$ & \\
\hline \multirow{2}{*}{ Gender } & Male & 137 & I7-Mar & $4 I$ & 23 & 0.816 \\
\hline & Female & 110 & 75.9 & 35 & 24.1 & \\
\hline \multirow{3}{*}{ Being repeatedly insulted, assaulted, or threatened while being in duty } & Yes & 201 & 80.1 & 50 & 19.9 & $0.004^{*}$ \\
\hline & & & & & & \\
\hline & No & 46 & 63.9 & 26 & 36.1 & \\
\hline
\end{tabular}




\begin{tabular}{|c|c|c|c|c|c|c|}
\hline & & \multicolumn{4}{|c|}{$\begin{array}{l}\text { Are you thinking of leaving } \\
\text { Iraq }\end{array}$} & \multirow{3}{*}{$\begin{array}{l}\mathbf{P} \\
\text { Value }\end{array}$} \\
\hline & & \multicolumn{2}{|l|}{ Yes } & \multicolumn{2}{|l|}{ No } & \\
\hline & & No. & $\%$ & No. & $\%$ & \\
\hline \multirow{2}{*}{ Exposure to any sort of violence while being in duty } & Yes & 167 & 19-Mar & 43 & 20.5 & 0.078 \\
\hline & No & 80 & I0-Mar & 2-Feb & 29.2 & \\
\hline \multirow{2}{*}{ Exposure to any sort of violence out of duty } & Yes & 103 & 85.8 & I7-Jan & 14.2 & $0.002 *$ \\
\hline & No & 144 & 70.9 & 59 & 29.1 & \\
\hline \multirow{2}{*}{$\begin{array}{l}\text { Forced to pay a (Tribal penalty) for the medical/ surgical complications of the } \\
\text { patients }\end{array}$} & Yes & 29 & 87.9 & 4 & 12.1 & 0.103 \\
\hline & No & 218 & 75.2 & 72 & 24.8 & \\
\hline \multirow{2}{*}{ Being arrested, kidnapped, or injured (violently) during the last 10 years } & Yes & 49 & 81.7 & II & 18.3 & 0.293 \\
\hline & No & 198 & 75.3 & 5-Mar & 24.7 & \\
\hline \multirow{2}{*}{ Family members being killed, kidnapped, or injured (violently) in the last 10 years } & Yes & 112 & 82.4 & 24 & 17.6 & $0.034 *$ \\
\hline & No & 135 & 72.2 & 52 & 27.8 & \\
\hline \multirow{2}{*}{ Seniors/ colleagues being killed, kidnapped, or injured (last 10 years) } & Yes & 194 & 78.2 & 54 & 21.8 & 0.176 \\
\hline & No & 53 & 70.7 & 22 & 29.3 & \\
\hline \multirow{2}{*}{ Exposure to any kind of pressure while doing their job } & Yes & 203 & 79 & 54 & 21 & $0.035^{*}$ \\
\hline & No & 44 & 66.7 & 22 & 33.3 & \\
\hline \multirow{2}{*}{ Going outside Iraq is safer for doctors } & Yes & 235 & 81.3 & 54 & 18.7 & $0.0001 *$ \\
\hline & No & 12 & 35.3 & 22 & 64.7 & \\
\hline \multirow{2}{*}{ Any chance Iraq will be a suitable place to live in the near future? } & Yes & 37 & 58.7 & 26 & 41.3 & $0.0001 *$ \\
\hline & No & 210 & 80.8 & 50 & 19.2 & \\
\hline
\end{tabular}

*Significant difference in proportions using Pearson Chi-square test at 0.05 level.

\section{Discussion}

The 323 junior doctors in our study aged between 24-39years, which indicates that they lived and grew up during the period of instability that the Iraqis experienced over the last 36years, ${ }^{19,20}$ during which the cohort of Iraqi children and youth (some of whom are now included in our study) have been so greatly affected by horrible events, they were facing very real dangers of disease, starvation, psychological trauma and death, ${ }^{21}$ such conditions make people less resilient to adverse experiences later in their life. ${ }^{22}$ The participants showed different responses to the status of severe stress that all the Iraqis are experiencing, especially the forms of violence they are facing during (and out of) their duty. Half of them stated that the highest risk on their life was at the work place which gives an impression about the pressure (physical, psychological and social) they are subjected to. More than three quarters of the sampled doctors reported exposure to insult, assaults, or threats (sometimes by gun) when they were in duty, and about two thirds exposed to different forms of violence, $10 \%$ experienced what is called "Tribal penalty" that is when any complications happened to the patient, then his relatives (tribe) may force the doctor to pay a compensation that may reach $\$ 1,00,000$ otherwise he may get himself killed (and this has happened several times). The results also revealed that about fifth of the respondents were exposed to either arrest, kidnapping or intentional injuries. Such trauma usually causes adverse psychological effects that may last for a very long time, may interfere with their capability, and inversely reflected on the quality of health services they are affording to the community. The doctors (42.1\%) also reported that members of their families have been either killed, kidnapped or injured, and more than three quarters reported that the same thing happened to their colleagues during the last ten years of instability in Iraq(sectarian war, car bombing, assassinations and mass violence). This "unrest" situation will not only affect their performance in their sensitive job, but it will also create a sense of panic that may push them forcefully to leave their country to escape the risk of death or disability. Most of the doctors, especially those who were exposed (or any of their family members or colleagues) to any form of violence, stated that it is safer to leave the country, this is consistent with a study conducted on Iraqi medical doctors and revealed that doctors abroad describe better work atmospheres, job satisfaction, and training quality, of those, more than half have left Iraq for security reasons. ${ }^{23}$ On a scale of 1 (minimum) to 10 (maximum); More than $93 \%$ leveled the risk to be more than 5 , about $90 \%$ think that it is more safe to be outside Iraq, as it is unlikely (by $80 \%$ of them) that the situation in Iraq is going to be improved in the near future. That's why more than three quarters of those junior doctors (with no significant gender difference) are already thinking of leaving Iraq. All the doctors reported that many of their seniors or colleagues have left the country as a defense mechanism to threats of violence. This means that the old traditional theory of "brain drain" (pulling the bright eastern brains by the western countries), has been now changed to a new theory of "brain push" by their own countries.

Many studies estimated that $15 \%$ of Iraq's population fled their homes internally and externally. ${ }^{24-26} \mathrm{~A}$ recent estimation by the 
Internal Displacement Monitoring Center (IDMC) revealed that Iraq currently has more than four millions internally displaced persons (IDPs), $10.8 \%$ of its population and $10 \%$ of IDPs worldwide. ${ }^{27}$ This flight included many academics and medical doctors who became targets of criminal or sectarian violence. ${ }^{28}$ Violence against doctors reports suggest that assassinations of doctors and out-migration rate that was peaked at 2006 have continued, most of the doctors now leaving Iraq are new graduates seeking security, better training and promising careers outside. ${ }^{11,29}$

\section{Limitations}

The sample included only junior doctors from Baghdad hospitals, however, more than $20 \%$ of the sample was doctors graduated from other governorates who have (only recently) moved to work in Baghdad, so we think that the sample is representative taking that the security situation does not differ a lot in most of the governorates (excluding Kurdistan region). The sample was relatively small, might be attributed to that it was sometimes difficult to catch the doctors when they are in duty, on the other hand, some doctors were cautious of telling such information (which they think is sensitive) due to the general concept of fear that is overwhelming in the country, yet, we think that increasing the sample size will not affect the outcome as there was a clear similarity in most of the responses.

\section{Conclusion}

The findings depict a cohort of junior doctors that are not satisfied with their career, or with their living status that is of high risk and gloomy future. They love their country but this dangerous love may threaten their life or, at least, question their future. The continuous depletion of brains and expertise will seriously affect the staffing level (quantitatively and qualitatively) leading to more deterioration in the quality and availability of the (currently limping) health care services.

\section{Acknowledgements}

None.

\section{Conflict of interest}

The author declares no conflict of interest.

\section{References}

1. Nelson R. Tackling violence against health-care workers. Lancet 2014;383(9926):1373-1374.

2. Jalili I. Iraqi academics and doctors: Innocent victims of a wider geopolitical struggle. Humanities. 2007;22:23.

3. Alwan NA. The killing of doctors in Iraq must stop. BMJ. 2011;343:d4467.

4. Lafta M, Pandya A. Verbal and physical aggression against resident physicians in two general hospitals in Baghdad. Journal of Muslim Mental Health. 2006;1(2):137-144.

5. Ihsanoglu E. Assessing the human tragedy in Iraq. International Review of the Red Cross. 2007;89:915-927.

6. Dyer O. Iraqi healthcare system still crippled five years after invasion, says report. BMJ. 2008;336(7636):113.

7. Webster P. Medical faculties decimated by violence in Iraq. CMAJ 2009;181(9):576-578.
8. Webster P. Iraq's health system yet to heal from ravages of war. Lancet. 2011;378(9794):863-866.

9. Brookings Institution and the Saban centre for Medal East policy. Tracking variables of reconstruction \& security in post-Saddam Iraq. Washington, USA; 2011.

10. Quinn J, Hnilicova H, Mensah E, et al. Iraqi physician brain drain in prolonged conflict. New Iraqi Journal of Medicine. 2011;7(1):88-98.

11. Al-Khalisi N. The Iraqi medical brains drain: a cross-sectional study. Int J Health Serv. 2013;43(2):363-378.

12. Burnham GM, Lafta R, Doocy S. Doctors leaving 12 tertiary hospitals in Iraq, 2004-2007. Social Science Medicine. 2009;69:172-177.

13. Doocy S, Malik S, Burnham G. Experiences of Iraqi doctors in Jordan during conflict and factors associated with migration. Am J Disaster Med. 2010;5(1):41-47.

14. O'Hanlon ME, Livingston I. Iraq Index: Tracking Variables of Reconstruction \& Security in Iraq. USA: Brookings Institution; 2011.

15. World Health Organization: World health statistics. Global Health Observatory (GHO) data. 2012.

16. Alwan A. Health in Iraq, the Current Situation, Our Vision for the Future and Areas of Work. 2nd ed. Ministry of Health; 2004.

17. The World Bank. Physician per 1,000 people.

18. Taylor AL, Hwenda L, Larsen B, et al. Stemming the brain drain-a WHO global code of practice on international recruitment of health personnel. N Engl J Med. 2011;365(25):2348-2351.

19. Fearson JD. Iraq's civil war. Foreign Affairs. 2007;86(2):2-15.

20. Al Hilfi k, Lafta R, Burnham G. Health services in Iraq. Lancet. 2013;381(9870):939-948.

21. Al-Jawadi A, Abdul-Rhman S. Prevalence of childhood and early adolescence mental disorder among children attending primary health care centers in Mosul, Iraq:a cross-sectional study. BMC Public Health. 2007; 7:274-282

22. Al Shawi AF, Lafta RK. Relation between childhood experiences and adults'self-esteem: A sample from Baghdad. Qatar Med J. 2014;2014(2):82-91.

23. Afram TZ. Posttraumatic stress disorder among the staff of Causality Departments in Mosul city. A Fellowship Thesis, Iraqi Board for Medical Specialization/psychiatry; 2007.

24. Morton M, Burnham G. Iraq's internally displaced persons. JAMA. 2008;300(6):727-729.

25. Mowafi H, Spiegel P. The Iraq refugee crisis. JAMA. 2008;299(14):17131715.

26. Lafta R, Aflouk N, Dhiaa S, et al. Needs of Internally displaced women and children in Baghdad, Karbala and Kirkuk. PLOS Currents: Disasters. 2016.

27. Internal Displacement Monitoring Centre. Global Overview People internally displaced by conflict and violence. 2015.

28. Salman S. A letter for a rheumatology colleague in Baghdad. J Clin Rheumatol. 2006;12(5):267-268.

29. Burnham G, Malik S, Al-Shibli AS, et al. Understanding the impact of conflict on health services in Iraq: Information from 401 Iraqi refugee doctors in Jordan. Int J Health Plann Manage. 2012;27(1):e51-e64. 